This article was downloaded by: [National Taiwan University]

On: 5 November 2008

Access details: Access Details: [subscription number 788846380]

Publisher Taylor \& Francis

Informa Ltd Registered in England and Wales Registered Number: 1072954 Registered office: Mortimer House, 37-41 Mortimer Street, London W1T 3JH, UK

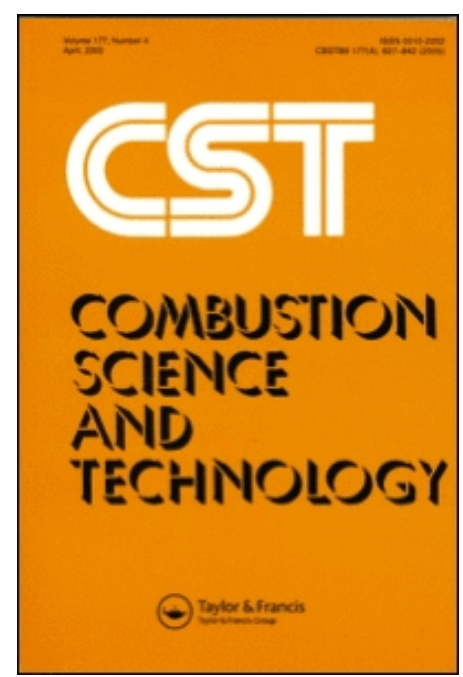

Combustion Science and Technology

Publication details, including instructions for authors and subscription information:

http://www.informaworld.com/smpp/title content=t713456315

\title{
ON THE BURNING CHARACTERISTICS OF COLLISION-GENERATED
} WATER/HEXADECANE DROPLETS

\section{H. Wang a; C. Z. Lin a; W. G. Hung a; W. C. Huang a; C. K. Law ${ }^{\text {b }}$}

a National Taiwan University, Department of Mechanical Engineering, Taipei, Taiwan, Republic of China ${ }^{b}$

Princeton University, Department of Mechanical and Aerospace Engineering, Princeton, New Jersey, USA

Online Publication Date: 01 January 2004

To cite this Article Wang, C. H., Lin, C. Z., Hung, W. G., Huang, W. C. and Law, C. K.(2004)'ON THE BURNING CHARACTERISTICS OF COLLISION-GENERATED WATER/HEXADECANE DROPLETS',Combustion Science and Technology,176:1,71 — 93

To link to this Article: DOI: $10.1080 / 00102200490255361$

URL: http://dx.doi.org/10.1080/00102200490255361

PLEASE SCROLL DOWN FOR ARTICLE

\footnotetext{
Full terms and conditions of use: http://www.informaworld.com/terms-and-conditions-of-access.pdf

This article may be used for research, teaching and private study purposes. Any substantial or systematic reproduction, re-distribution, re-selling, loan or sub-licensing, systematic supply or distribution in any form to anyone is expressly forbidden.

The publisher does not give any warranty express or implied or make any representation that the contents will be complete or accurate or up to date. The accuracy of any instructions, formulae and drug doses should be independently verified with primary sources. The publisher shall not be liable for any loss, actions, claims, proceedings, demand or costs or damages whatsoever or howsoever caused arising directly or indirectly in connection with or arising out of the use of this material.
} 


\title{
ON THE BURNING CHARACTERISTICS OF COLLISION-GENERATED WATER/HEXADECANE DROPLETS
}

\author{
C. H. WANG*, C. Z. LIN, W. G. HUNG, \\ AND W. C. HUANG
}

Department of Mechanical Engineering, National Taiwan University, Taipei, Taiwan, Republic of China

\author{
C. K. LAW \\ Department of Mechanical and Aerospace Engineering, \\ Princeton University, Princeton, \\ New Jersey, USA
}

\begin{abstract}
The combustion characteristics of freely falling droplets, individually generated by the merging of colliding water and hexadecane droplets, were investigated and compared with those for pure hexadecane and emulsified water/hexahexadecane droplets. The merging of the nominally nonmiscible hexadecane and water was manifested either in an apparently adhesive manner, or with the water droplet inserting into the hexadecane droplet. The latter, however, is the prevalent mode in hot environments and/or for droplet burning, provided the water volume fraction is less than 0.54 so it can be completely covered by hexadecane. Results on the combustion characteristics show that the ignition delay increases with increasing water content; that for the same droplet size it varies with $t_{\text {ig }}$ (hexadecane) $<t_{\text {ig }}$ (collision-generated) $<t_{\text {ig }}$ (emulsion); that the flame characteristics, including its color, were not affected by the water content; that droplet burning was terminated with either complete
\end{abstract}

Received 22 October 2002; accepted 7 July 2003.

The work at National Taiwan University was supported by the National Science Foundation of Taiwan, Republic of China, and that at Princeton University was supported by the U.S. Air Force Office of Scientific Research.

*Address correspondence to chinghua@ccms.ntu.edu.tw 
combustion, extinction, or microexplosion; and that the droplet volume at microexplosion is almost the same as the initial volume of water in the merged droplet. These results, together with considerations of the limit of superheat of water and the attainable droplet temperature, suggest that hexadecane was the primary and possibly only component undergoing gasification and subsequently combustion prior to the occurrence of microexplosion, and that microexplosion was predominantly induced by flash vaporization of the superheated water when it was exposed to the gaseous environment upon the near-complete gasification of the enveloping hexadecane component, instead of through homogeneous nucleation of the water component when it was still enveloped by hexadecane. With the aid of microexplosion, the effective burning rate $K_{\text {eff }}$ increased with increasing water content and for a given droplet size exhibited the ranking $K_{\text {eff }}$ (collision-generated) $>K_{\text {eff }}$ (emulsion) $>K_{\text {eff }}$ (hexadecane). The role of the air bubbles entrapped upon coalescence of the colliding droplets in facilitating microexplosion is also discussed.

Keywords: droplet collision, microexplosion

\section{INTRODUCTION}

The satisfactory performance of diesel engines is closely affected by the heterogeneous nature of the combustion processes, which can result in deleterious outcomes such as severe knocking as well as high emission levels of $\mathrm{NO}_{\mathrm{x}}$ and particulates including soot. Ever since Hopkinson (1913) sprayed water into a combustion chamber and successfully minimized knock, there has been substantial interest and, hence, research into the possibility of using water to modify the performance of diesel engines. In these studies, water was introduced into the combustion chamber via three means: (1) water injection into the air pathway, (2) direct water injection into the combustion chamber, and (3) emulsification of water and the liquid fuel before injection into the combustion chamber. Among these, the use of emulsions has been studied most extensively. For example, Valdmanis and Wulfhorst (1970), Greeves et al. (1976), and Murayama (1978) demonstrated soot reduction; Cornet and Nero (1955) and Wang and Ni (1996) reported improved fuel efficiency and reduced exhaust temperature; and Murayama (1978), Wang and Ni (1996), Turner and Siegmund (1973), and Owens and Wright (1976) noted reduced $\mathrm{NO}_{\mathrm{x}}$ emissions.

Fundamental studies on the combustion of water/oil emulsions was initiated by Ivanov and Nefedov (1965), who reported that suspended droplets of water/residual-oil emulsions underwent spontaneous explosion during combustion. It was further suggested that this so-called 
microexplosion event was responsible for the observed faster burning rate, improved combustion characteristics, and reduced smoke emissions. Microexplosion was also observed by Lasheras et al. (1979), Wang and Law (1985), and Wang and Chen (1996) in their free-droplet experiments. A comprehensive model was formulated by Law (1977) to describe the gasification mechanism of emulsions and the criterion governing the onset of microexplosion of emulsion droplets.

While these previous fundamental studies have attributed the reduction of the various deleterious heterogeneous effects associated with spray combustion to water emulsification, the effect of separate water injection has been considered to be largely caused by the lowering of the combustion environment temperature and the enrichment of its water concentration through water vaporization. In the present study we have, however, found that separate water injection can also affect the burning characteristics in a heterogeneous manner not unlike that due to emulsification. Specifically, we shall demonstrate in due course that when a fuel droplet collides with a water droplet, a single entity consisting of the nominally nonmiscible masses of the fuel and water is frequently formed. Microexplosion can again take place for such an entity and, consequently, leads to the various beneficial effects just described for water emulsification.

In the next section the experimental aspects on the investigation will be specified, which will be followed by presentation of the experimental results on the collision outcome, the flame characteristics, the states of ignition, microexplosion, extinction, and the burning rate of the these collision-generated droplets.

\section{EXPERIMENTAL APPARATUS AND PROCEDURE}

Figure 1 shows a schematic of the overall experimental setup. The first crucial requirement of the experiment was to generate spatially and temporally stable droplets over extended periods of time. The present study adopted a modified ink-jet printing technique (1996), in which a circular piezoelectric crystal plate was used to squeeze out the liquid fuel through a small glass nozzle to form the droplets. Two such droplet generators, with the same phase-shifted pulse rate but different pulse width and amplitude, were used to generate two stable streams of droplets with different or equal sizes. The second crucial requirement was to have these fine droplets collide in a desired manner. This was accomplished by adjusting the trajectories of the two streams on the same 


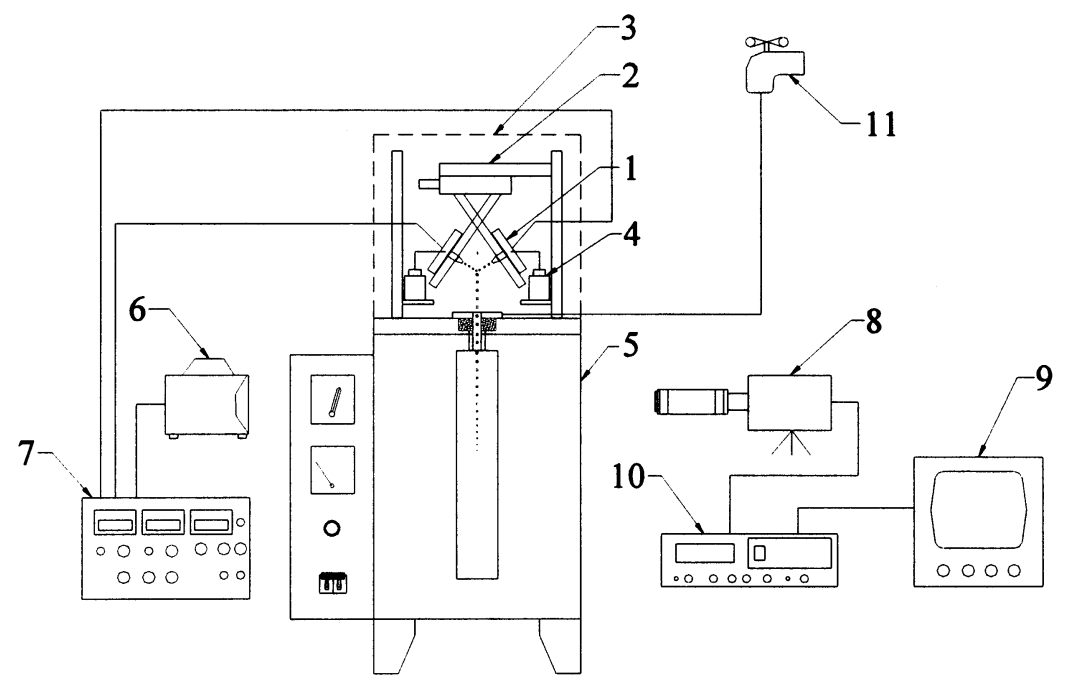

Figure 1. Schematic of the experimental setup.

plane and by varying the phase difference and/or the relative positions of the two generators. By further seating the generation assembly on additional two-axes translator, the collided droplets could then be adjusted to fall through a small vertical channel into the high-temperature, oxidizing environment in which the droplet ignited and burned.

The high-temperature furnace used nickel chromium wire for heating, fire brick for wall insulation, and has a temperature range from room temperature to $\sim 1050^{\circ} \mathrm{C}$ controlled by a thermostat and monitored by a thermocouple. Circulating water was used to separate the droplet generation devices from the high-temperature environment. Quartz windows on both sides allowed observation and photography.

A strobe light, synchronized but phase-shifted with the droplet generator, was used to freeze the moving droplets at various stages. Enlarged droplet images were recorded by a CCD camera with a Baush \& Lomb mono-zoom-7 long focus microscopic lens. The uncertanity in the determination of the droplet size was about $2 \%$, mainly from reading the boundary of the droplet image.

The droplet size was varied by altering the size of the glass nozzle as well as the width and/or amplitude of the pulse of the generator. In the study, $n$-hexadecane was chosen as the test fuel because of its relevance to diesel fuels and because of its high boiling point, which would facilitate 
microexplosion. In the experiments, the size of the hexadecane droplet was fixed at $302 \mu \mathrm{m}$ and that of the corresponding water droplet was varied from 68 to $\sim 400 \mu \mathrm{m}$. Thus, the size of merged droplets varied from 302 to $\sim 450 \mu \mathrm{m}$, with the volume fraction of water ranging from 0 to $\sim 0.70$. To account for the effect of the droplet size on the burning characteristics, data of pure hexadecane droplets, with sizes of 302 to $415 \mu \mathrm{m}$, were also determined for comparison.

Technical-grade $n$-hexadecane with purity greater than $99 \%$ was used. The droplet burning characteristics studied include ignition delay, burning rates, extinction, and microexplosion.

The ignition delay $t_{\text {ig }}$ was defined as the time interval from the instant at which the droplet was first exposed to the high-temperature environment to when a visible flame was observed, and it could be easily determined through the synchronized strobe. The experimental resolution of the timescale of the electric device was $\pm 0.04 \mathrm{~ms}$, and the uncertainty in defining the ignition point was estimated to be $1 \mathrm{~ms}$. The droplet generation frequency was about $30 \mathrm{~Hz}$. The droplets were separated by over 100 diameters such that there was essentially no droplet interaction effect, as noted previously by Sangiovanni and Kesten (1977). They also reported that the ignition delay decreased with increasing relative velocity between the droplet and the environment, but the effect was minor. Because the droplet relative velocities in the present experiments were in the same range as those of Sangiovanni and Kesten (1977), the influence of the relative velocity was not specifically checked.

Figure 2 shows the temperature profiles along the center of the connection channel and the furnace at two different temperature settings. The $950^{\circ} \mathrm{C}$ setting was used in the experiments. It can be seen that there exists a certain range through which the center temperature increases and eventually reaches the final temperature. For most test conditions droplet ignition actually took place within this transient region. Considerable effort was expended toward minimizing this nonuniform temperature region relative to the ignition delay, and the present experimental design and procedure were consequences of the best of such efforts. It may be noted that, judging from the experimental design and procedure adopted in previous studies involving either suspended and freely falling droplets, it appears that the ignition delays in these previous studies must also be very much under the influence of some initial temperature nonuniformity. Thus, ignition delays obtained from studies of this nature are more of a relative nature, showing the global, trendwise behavior for the ambient temperature indicated. 


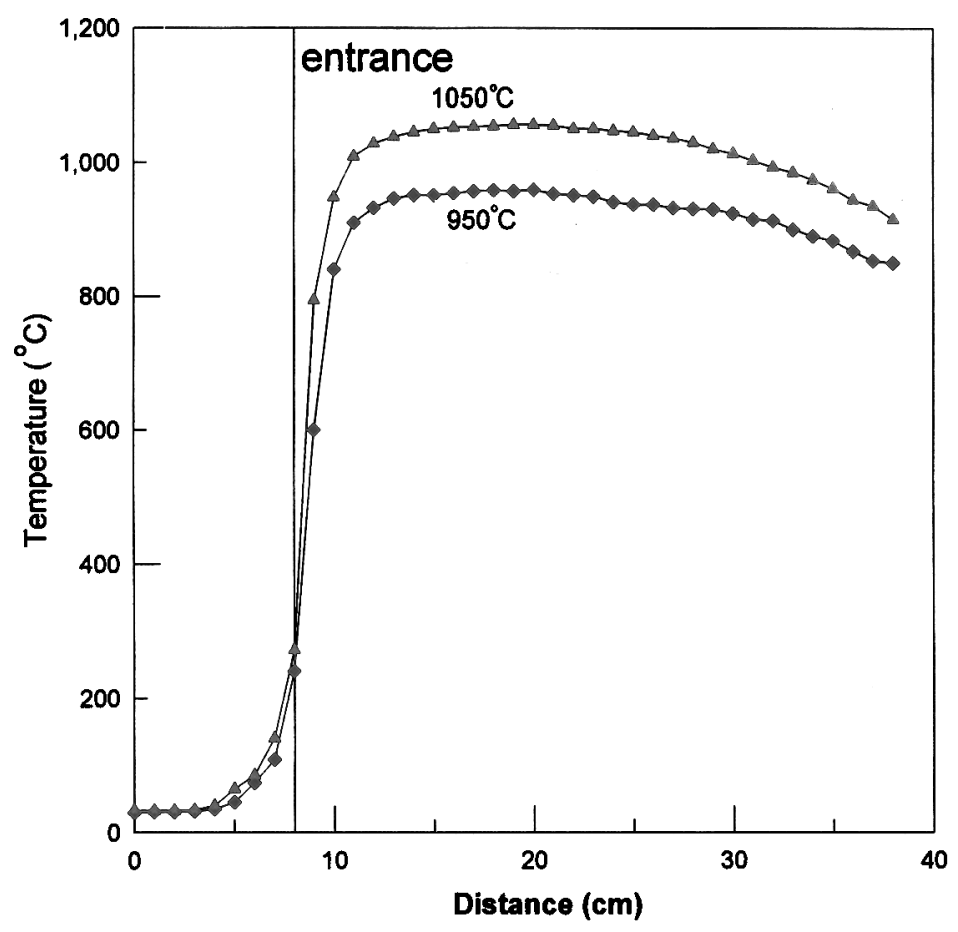

Figure 2. Temperature distributions along the furnace center.

The droplet combustion process was assessed through visual observation of the flame streak, while its gasification rate was quantified by determining the temporal variation of the droplet size through microphotography of the stroboscopically backlighted droplet images. The independently generated or collision-generated droplets were basically spherical when entering the combustion chamber.

It is also emphasized that because of the repeatability and stability of the droplet streams, each data point in the following figures actually represents thousands of test droplets.

\section{RESULTS AND DISCUSSION}

\section{Collision Outcome of Hexadecane and Water Droplets}

In all previous studies on droplet collision (Ashgriz and Givi, 1987; Ashgriz and Poo, 1990; Jiang et al., 1992; Qian and Law, 1997), the two 
colliding droplets were of the same liquid and, hence, were miscible. It was consequently shown that, depending on the impact Weber number and the extent of off-centeredness, the collision could result in either merging, bouncing, or merging followed by separation with the concomitant production of one or more satellite droplets. Similar behaviors were also observed in a recent study on droplet collision involving two different liquids that were, however, still miscible (Wang et al., 2003).

In the present study, the liquids constituting the two colliding droplets, namely water and hydrocarbon, were not miscible. This then immediately led to the anticipation that droplet merging was not possible, and that bouncing could be the only collision outcome. It is thus somewhat surprising that our experiments demonstrated, perhaps for the first time, that (macroscopic) merging of the colliding droplets was actually observed. The merging can be further divided into two modes, namely, adhesive merging and insertive merging. For adhesive merging the colliding droplets appeared to be in contact with each other, although a boundary indicating a contact surface clearly existed. For insertive merging the water droplet was "swallowed" into the interior of the hexadecane droplet and, hence, was enclosed by hexadecane.

Figure 3 shows the photographic images of some typical collision sequences. Basically, the merging was adhesive when the relative velocity was low and the collision momentum could not overcome the surface tension, whereas the merging was insertive for higher collision velocities, as shown in Figure $3 a$. By keeping a high relative velocity and increasing the off-center distance of the two droplets, the insertive merging mode would change to the adhesive merging mode, as shown in Figures $3 b$ and $3 c$ for different droplet sizes. Mechanistically, since the surface tension of water is larger than that of hexadecane, insertive merging was observed for most of the cases in the study. However, when the size of the water droplet was larger than that of the hexadecane droplet, say 320 vs. $302 \mu \mathrm{m}$, the hexadecane droplet could no longer completely cover the water droplet. For such cases part of the water droplet was always exposed to the environment.

The ambient and, hence, droplet temperature also appeared to affect the specific mode of merging through the variation of the surface tension. It was observed that while an adhesively merged droplet would remain in this state for a long time at room temperature, the water component would be swallowed by the hexadecane component when the merged droplet passed through the connection channel and entered the 

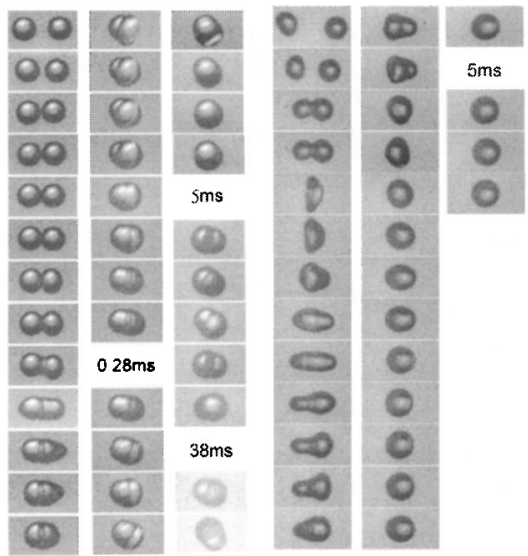

adhesive merging

$$
\mathrm{B}=0
$$

$\mathrm{V}_{\text {rel }}=0.93 \mathrm{~m} / \mathrm{s} \quad \mathrm{V}_{\text {rel }}=2.15 \mathrm{~m} / \mathrm{s}$

water $300 \mu \mathrm{m}+\mathrm{n}$-hexadecane $302 \mu \mathrm{m}$

3(a)
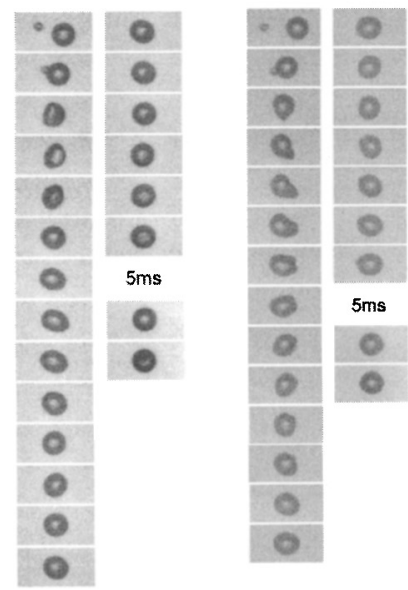

insertive merging adhesive merging

$\mathrm{B}=0$ $\mathrm{B}>0$

$\mathrm{V}_{\text {rel }}=2.19 \mathrm{~m} / \mathrm{s}$

water $102 \mu \mathrm{m}+\mathrm{n}$-hexadecane $302 \mu \mathrm{m}$

3(c)
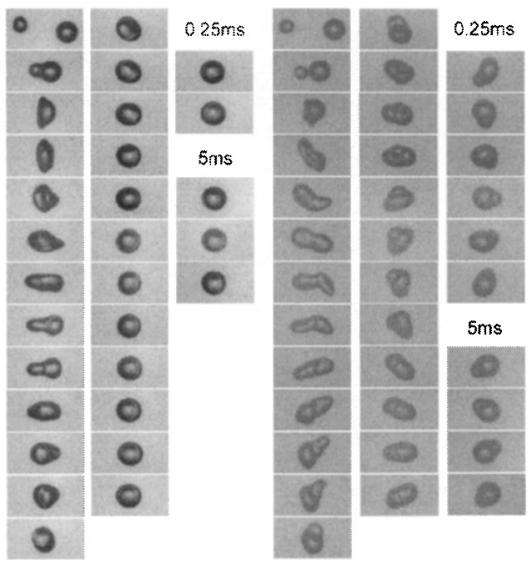

insertive merging adhesive merging $\mathrm{B}=0$ $\mathrm{B}>0$ $\mathrm{V}_{\mathrm{rel}}=2.85 \mathrm{~m} / \mathrm{s}$

water $235 \mu \mathrm{m}+\mathrm{n}$-hexadecane $302 \mu \mathrm{m}$

3(b) 
high-temperature furnace. Thus, in the present study, the burning characteristics largely corresponded to those of the insertive merging mode, regardless of whether the original mode was adhesive or insertive.

A careful examination of the recorded image revealed the presence of one or more "black" spots upon merging. These black spots were also observed in the experiments of Ashgriz and Poo (1990), Jiang et al. (1992), and Wang et al. (2003). They were classified (Wang et al., 2003) as the air bubbles trapped within the droplet, either through droplet collision and merging or unstable droplet formation with ligament reattachment. In the study of Wang et al. (2003) these trapped air bubbles played an essential role in inducing internal gasification and thereby droplet microexplosion. We shall discuss shortly that they seemed to play a lesser role in microexplosion for the present immiscible water/hexadecane droplets.

\section{Flame Characteristics}

Once the droplet was ignited, a steady flame streak was observed (Figure 4). For a pure hexadecane droplet, the flame was blue for a short distance from ignition. It then became white-yellow inside and blue outside for a large portion of the burning trajectory, and finally turned to blue again as the droplet became small. A yellow sparkling flame was sometimes observed toward the end and was likely caused by the minor impurity species within the fuel. These characteristics are consistent with the understanding that during droplet burning a soot layer is formed in the inner region of the flame where Stefan convection balances thermophoretic convection and that such a balance cannot be achieved when the droplet becomes too small.

The color of the flame for the collision-generated, bicomponent, water/hexadecane droplet was largely similar to that of the pure hexadecane droplet for the first two periods. The burning, however, terminated in four different kinds of manners depending on the water content. In particular, for water content less than $4 \%$ (zone 1), the flame streak terminated with a slightly enlarged white-yellow sparkle somewhat similar to that of the pure hexadecane droplet. For water contents between 4 and about $10 \%$ (zone 2), the flame streak terminated with extinction and the droplet could still be observed after the disappearance of the flame. For water contents between 10 and 17\% (zone 3), the flame again appeared to be extinguished. However, the droplet was only 


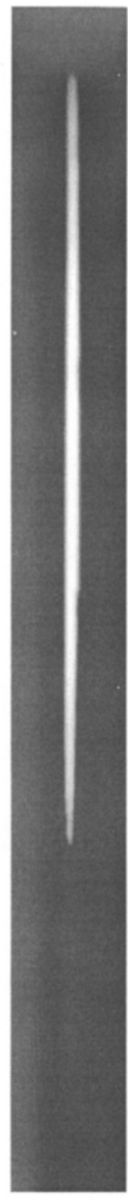

0

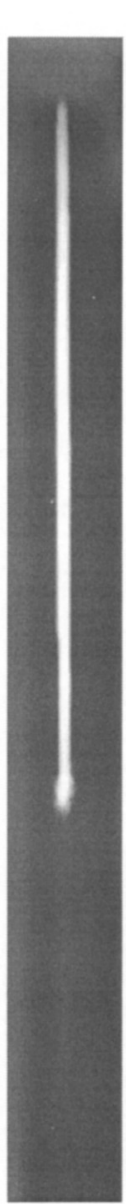

0.01

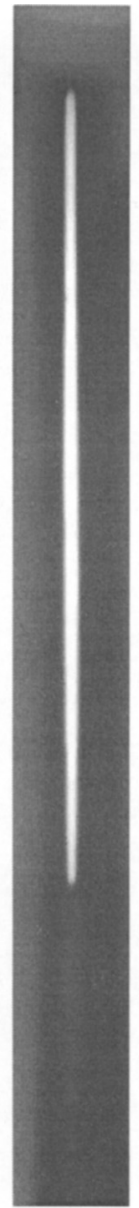

0.04

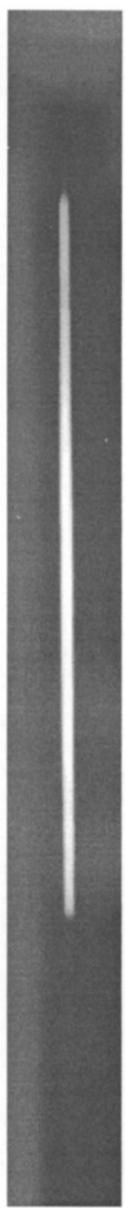

0.32

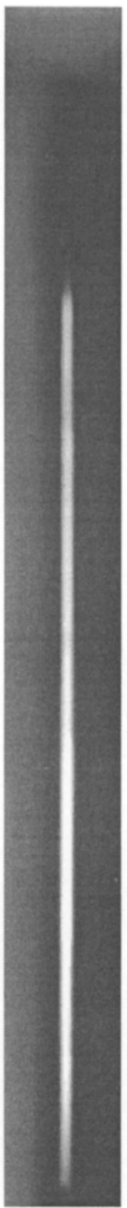

0.5

(a)

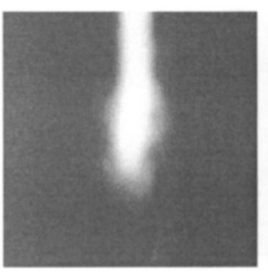

0.01

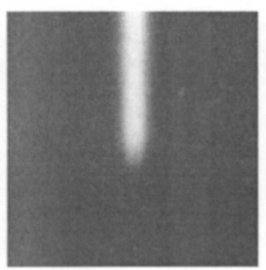

0.04

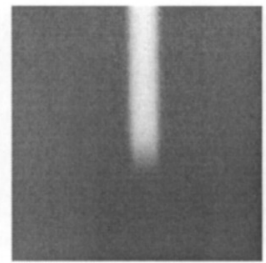

0.32

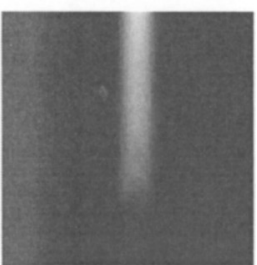

0.5

(b)

Figure 4. (a) Flames for different water volume fractions; (b) enlarged photos at flame tip. 
occasionally observed, implying the likelihood that it had exploded under most situations. For water contents in the range of 17 to $54 \%$ (zone 4), the flame clearly terminated with droplet explosion, accompanied by a violent explosive sound. The flame color was faint white and was observable only with great care. Occasionally, with the same water content, microexplosion occurred much earlier, as can be seen from Figure 5. This is believed to be caused by the presence of the air bubble trapped at the interface of the merged water/hexadecane mass.

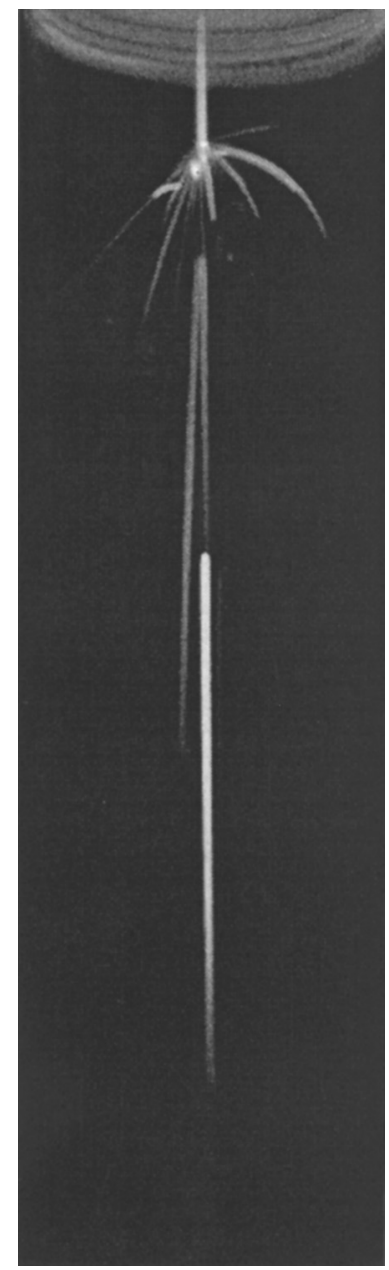

Figure 5. Flame for the facilitated explosion. 
The explosion, however, was not so violent, producing flame branches having the same characteristics as those of the primary flame streak. Ignition was not possible for water contents higher than those of zone 4, corresponding to larger water droplets.

For the flame color of emulsified water/hexadecane droplets, it is recognized that due to the presence of water vapor around the droplet, the flame temperature as well as the soot formation tendency should both decrease. Consequently the flame was fainter and became progressively reddish (Wang and Chen, 1996; Wang and Law, 1985) as the water content increased. Furthermore, there were continuous weak explosions and tiny mass ejections along the burning trajectory.

\section{Ignition Delays}

To facilitate interpretation of the ignition results, we note that there are two factors that affect droplet ignition. First, the droplet has to be sufficiently heated such that enough fuel vapor is generated at the droplet surface. Second, this fuel vapor needs to diffuse outward, locally mix with the oxidizer gas from the ambience, and undergo chemical reaction to the extent that a runaway situation is achieved. These two factors respectively contribute to the physical and chemical delays of the overall ignition process and may or may not overlap substantially when considering the overall ignition delay (Law, 1978). The physical delay is expected to the controlled by the physical properties of the fuel such as the droplet size, the heat capacity, and the boiling point and latent heat of vaporization of the fuel. The chemical delay is controlled by the chemical properties of the fuel, primarily its pyrolytic and oxidative characteristics. The process of fuel-oxidizer mixing can also be intricately couple to the chemical delay.

Figure 6 shows the ignition delays of the (collision-generated) bicomponent droplets, with the size of the colliding hexadecane droplets fixed at $302 \mu \mathrm{m}$ and that of the colliding water droplets varied from 68 to $320 \mu \mathrm{m}$. Ignition was not possible for water droplets greater than $\sim 320 \mu \mathrm{m}$ in the present experiment. Since the size of the bicomponent droplet varied with the water content, the ignition delays of pure hexadecane with different droplet sizes were also experimentally determined to account for the size effect. Figure 6 then shows that the ignition delay for hexadecane droplets increased with increasing droplet size, which is consistent with previous results (Wang and Chen, 1996) and is reasonable because of the increased need for droplet heating (Law, 1978). 
zone 1: microexplosion (water: 0 0.1mm)

zone 2: extinction (water: $0.1 \sim 0.14 \mathrm{~mm}$ )

zone 3: transition (extinction or micro-explosion) (water: $0.14 \sim 0.18 \mathrm{~mm}$ )

zone 4: microexplosion (water: 0.18 0.32mm)

zone 5 : can not be ignited (water: $>0.32 \mathrm{~mm}$ )

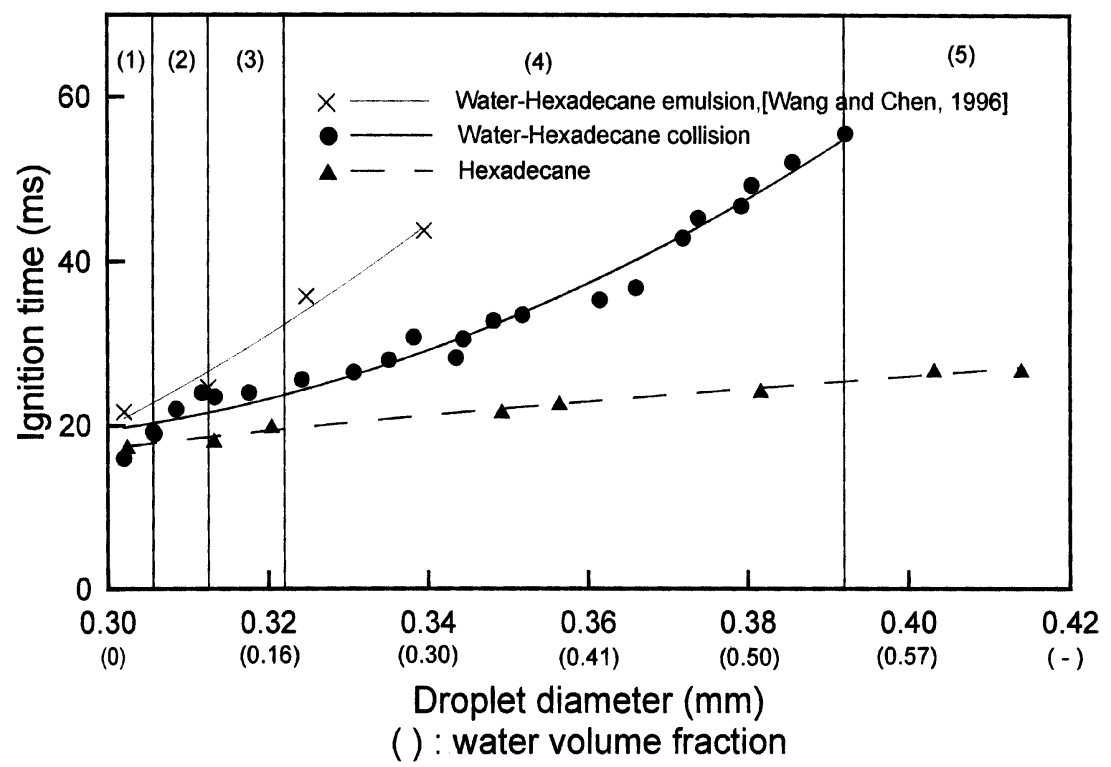

Figure 6. Ignition delays of collision-generated and pure hexadecane droplets.

Referencing the ignition delays of the bicomponent droplets to those of the pure hexadecane droplets, it is then obvious that for the same droplet size the bicomponent droplets took longer to ignite. This behavior can be explained by first recognizing that since water was embedded within hexadecane in the bicomponent droplet, only hexadecane was vaporized at the droplet surface. Consequently, from the chemical point of view, there should be no difference in the ignition mechanism between the hexadecane droplet and the bicomponent droplet. Thus, the observed difference in the ignition delay should be physical in nature, most likely caused by the higher value of the heat capacity of water, which slowed down the rate of temperature increase of the bicomponent droplet and, hence, led to an increase in the physical delay.

By further comparing the preceding results with those of water/ hexadecane emulsions obtained previously (Wang and Chen, 1996), it is 
seen (Figure 6) that the ignition delays for the emulsion droplets were substantially longer. This is reasonable in that the water microdroplets within the emulsion were continuously exposed at the surface of the emulsion droplet and thereby actively participated in the gasification process (Law, 1977). Its larger latent heat of vaporization prolonged the droplet's heating period, while the presence of its vapor also diluted the fuel concentration in the gas and, hence, reduced the chemical reactivity. Thus, both the physical and chemical delays were increased for the emulsion droplet.

\section{Microexplosion}

As mentioned earlier, droplet microexplosion is a characteristic feature of water/hexadecane droplet combustion. Figure 7 shows some typical images of explosion. The size of the droplet at the state of explosion is shown in Figure 8 as function of the initial water content. Since the droplet disappeared immediately after explosion, the data were taken at

insertive adhesive

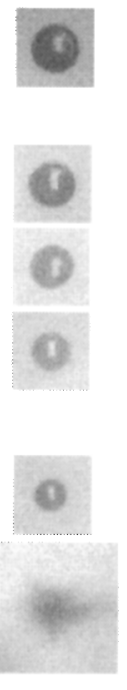

$235 / 302$
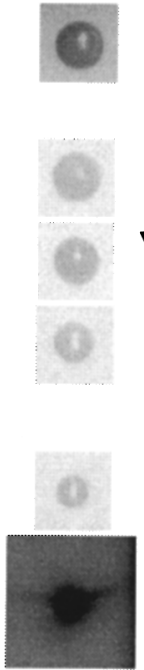

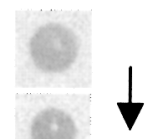

$\downarrow \quad 33.8 \mathrm{~ms}$

before explosion

$\mathrm{H}_{2} \mathrm{O} / \mathrm{C}_{16} \mathrm{H}_{34}$

\section{insertive adhesive}
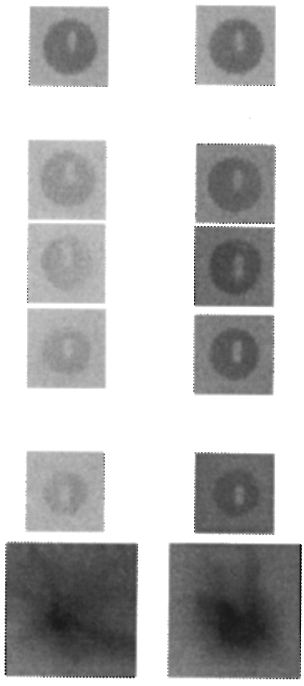

$300 / 302$

Figure 7. Photos of droplet rupture process of collision-generated droplets. 


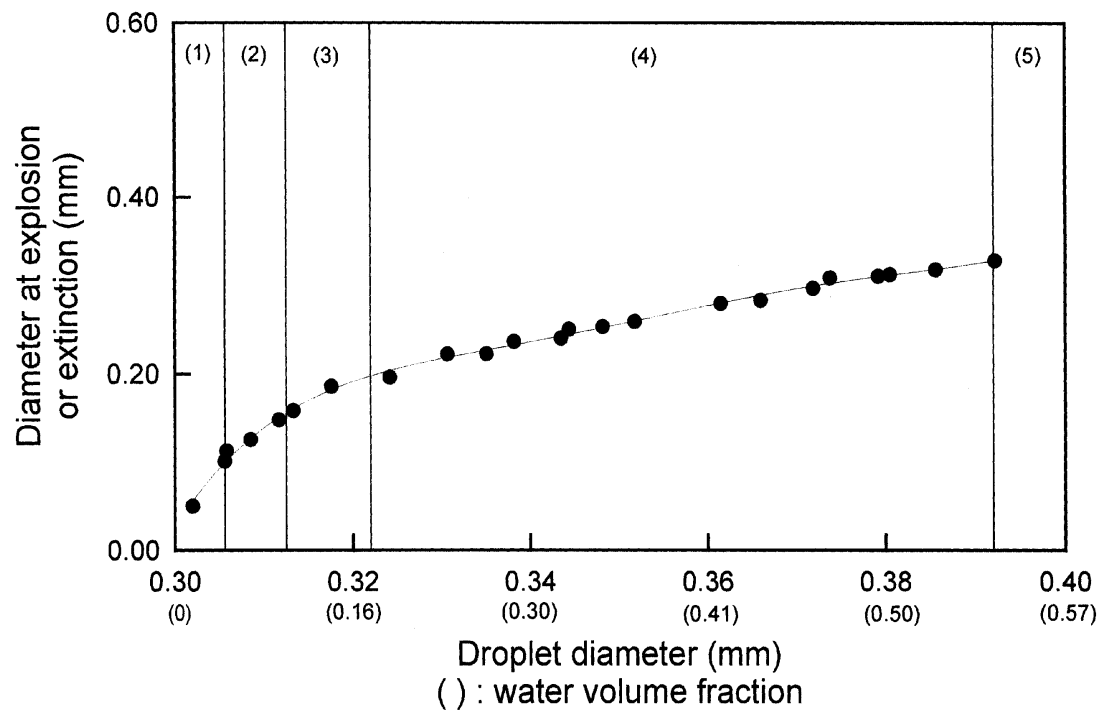

Figure 8. Droplet sizes at microexplosion or extinction of collision-generated droplets.

the state just before explosion. It is seen that the explosion size increased with increasing water content. Because the increase in the initial droplet diameter was due to the use of larger water droplets in the collision, in Figure 9 we have plotted the volume of the droplet at explosion as a function of the initial volume of water. It is then quite interesting to note that the droplet volume at microexplosion varies somewhat linearly with the initial volume of water, with a slope that is close to $45^{\circ}$.

The result of Figure 9 can be physically interpreted as follows. Since hexadecane was the only vaporizing component of the present collisiongenerated bicomponent droplet during burning, the droplet temperature was controlled by the boiling point of hexadecane $\left(287^{\circ} \mathrm{C}\right.$ at atmospheric pressure), and should be about tens of ${ }^{\circ} \mathrm{C}$ below this value. Because water boils at $100^{\circ} \mathrm{C}$, the embedded water droplet was substantially superheated in the absence of heterogeneous nucleation sites. The extent of superheat, however, was not expected to cause homogeneous nucleation because the limit of superheat of water is estimated to be between 290 and $310^{\circ} \mathrm{C}$ (Blander and Katz, 1975). Consequently, the bicomponent droplet would burn in the manner of a hexadecane droplet, without undergoing microexplosion through the homogeneous nucleation of water, until the fuel was practically all consumed. The superheated water droplet was then 


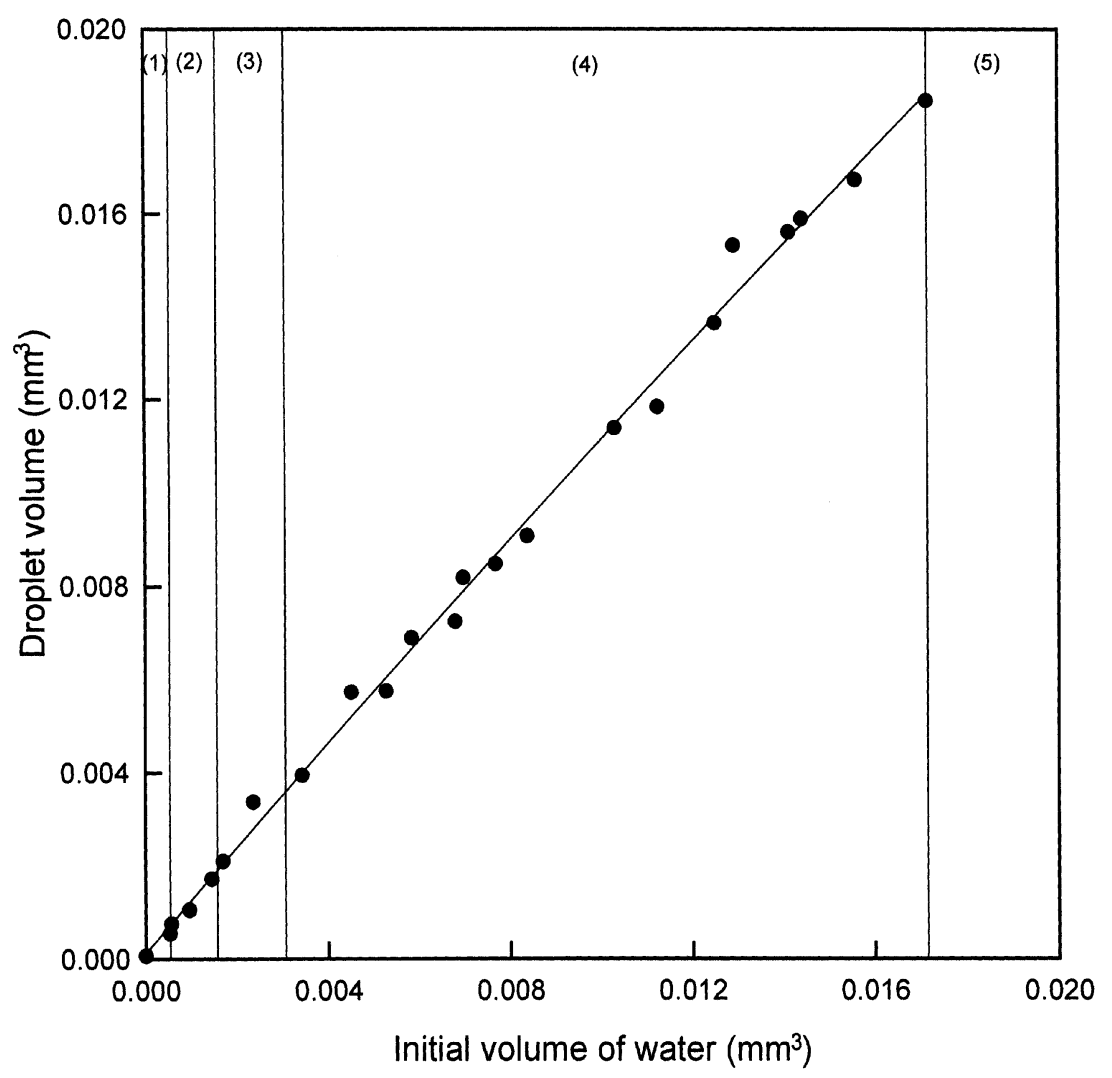

Figure 9. Droplet volumes at microexplosion or extinction as function of initial volume of water of collision-generated droplets. The various zones are defined in Figure 6.

exposed to the gaseous environment and was instantly gasified through the empirically observed phenomenon of flash vaporization.

The preceding mechanism then implies that the droplet at the state of microexplosion was primarily only water and that it should be the same amount as that contained within the initial droplet, as demonstrated in Figure 9. The fact that the slope of Figure 9 is not $45^{\circ}$ is due to thermal expansion of the droplet from the initial state of room temperature to that at explosion. Indeed, the present slope of about 1.15 would correspond to a volumetric expansion ratio of water from room temperature to $200^{\circ} \mathrm{C}$ (Weast, 1980), which can be considered close to the droplet temperature during steady burning. 
The preceding mechanism is also consistent with the microexplosion behavior of water/hexadecane emulsion droplets, characterized by the continuous ejection of small masses, ostensibly representing the dispersed water microdroplets in the emulsion, until complete depletion of the emulsion droplet.

We further note that early microexplosion was occasionally observed, although a consistent trend was not identified. Such facilitated microexplosion events were most likely caused by the trapped air bubbles at the interface between water and hexadecane upon droplet collision. They served as heterogeneous sites that induced nucleation at lower temperatures, ostensibly before the embedded water droplet was exposed to the ambience and flash vaporized. The intensity of such explosions, however, was weaker because of the reduced amount of superheat accumulated when it did occur. Because the dominant cause for droplet microexplosion was flash vaporization for present collision-generated water/hexadecane droplets, the trapped air bubbles played a less significant role in droplet microexplosion as for the previously observed collision-generated droplets of miscible fuels (Wand et al., 2003). More study, however, is warranted to identify a clear trend for such an advanced microexplosion mechanism, for example, by using fuels with boiling points higher than that of hexadecane to facilitate internal nucleation.

\section{Extinction}

For pure fuels, it is well established (Chung and Law, 1986; Law and Williams, 1972) that a sufficiently small fuel droplet may not sustain an enveloped flame because of the insufficient residence time available for near-complete reaction. Instead of complete burnout, a weakly burning droplet self-extinguishes as its size is reduced to a certain critical value that depends on the combustion conditions, such as the environment temperature, oxygen concentration, and pressure.

The present results showed that while hexadecane droplets burned almost to completion, extinction occurred for the bicomponent droplets with water contents varying from 4 to $10 \%$. The difference was likely caused by the higher demand for heating the embedded water droplet when the burning itself was already very weak as the droplet size steadily diminished. Microexplosion would not occur because the droplet was still covered by hexadecane when extinction occurs. The droplet, consisting of both water and hexadecane, would subsequently cool down. 
For higher water contents, extinction was caused by depletion of hexadecane as the chemical reactivity should still be fairly strong for the relatively large droplet size. In such cases extinction was immediately followed by droplet microexplosion in the manner described earlier.

\section{Burning Rates}

Because of the complexity of the burning phenomena for the collisiongenerated droplet, it is useful to define some global burning rates that account for the processes of ignition, steady burning, extinction, and microexplosion, based on the following measured values: initial droplet diameter $D_{0}$; the extinction and microexplosion droplet diameters, $D_{\text {ext }}$ and $D_{\exp }$, respectively; the actual burning time of the droplet $\Delta t_{1}$, which is the time between ignition and the occurrence of extinction or microexplosion of the droplet; and the droplet lifetime $\Delta t_{l}$, which is the time between the instant the droplet is first exposed to the hot environment and the occurrence of extinction or microexplosion. We can then define average, overall, and effective burning rates, $K_{\mathrm{ab}}, K_{\mathrm{ob}}$, and $K_{\mathrm{eff}}$, as

$K_{\mathrm{ab}}=\left(D_{0}^{2}-D_{\mathrm{ext}}^{2}\right) / \Delta t_{1} \quad$ and $\quad K_{\mathrm{ob}}=\left(D_{0}^{2}-D_{\mathrm{ext}}^{2}\right) / \Delta t_{l}$

for burning terminated by extinction, and

$K_{\mathrm{ab}}=\left(D_{0}^{2}-D_{\text {exp }}^{2}\right) / \Delta t_{1} \quad K_{\mathrm{ob}}=\left(D_{0}^{2}-D_{\text {exp }}^{2}\right) / \Delta t_{l} \quad$ and $\quad K_{\mathrm{eff}}=\left(D_{0}^{2}\right) / \Delta t_{1}$

for burning terminated by almost complete burning or by microexplosion. The physical implications of these defined quantities are discussed in the following.

Figure 10 plots the burning times and lifetimes of the collisiongenerated bicomponent droplets; the results of pure hexadecane with different sizes are also shown for comparison. The different burning rates as defined earlier are then shown in Figures 11-13. Because facilitated microexplosion induced by air bubble was only occasionally observed, and a clear trend had not been identified, results from these events were not included in the analysis.

It is seen from Figure 10 that both the burning and lifetimes of hexadecane increased with increasing droplet size, which is reasonable. 


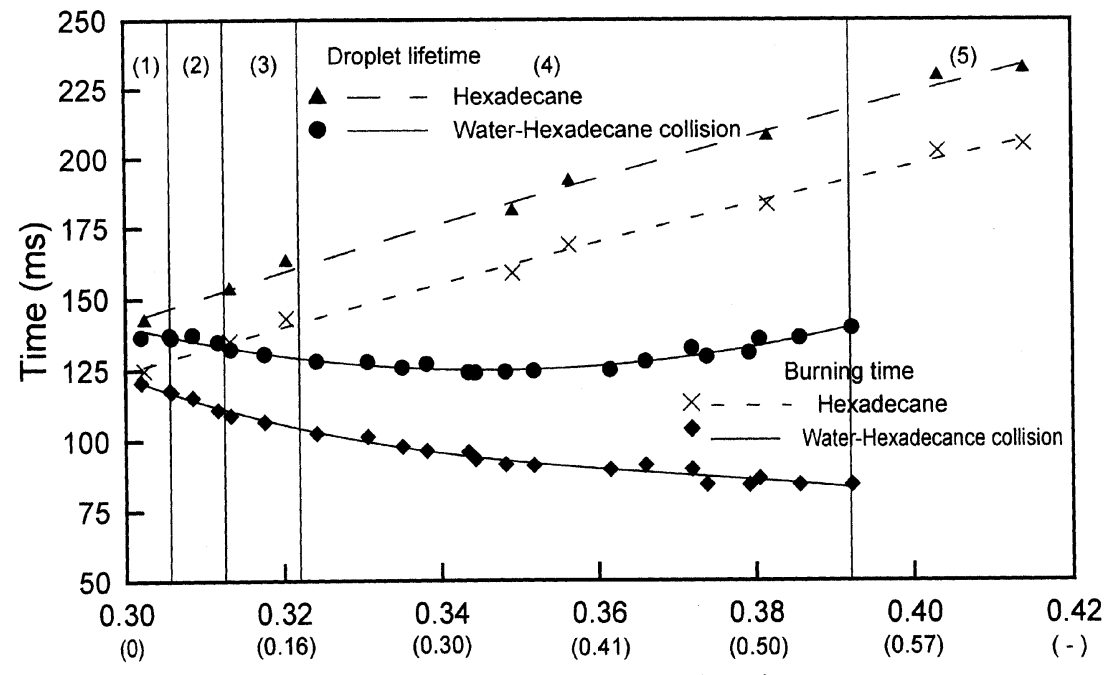

Droplet diameter $(\mathrm{mm})$

() : water volume fraction

Figure 10. Burning times and droplet lifetimes of collision-generated and pure hexadecane droplets. The various zones are defined in Figure 6.

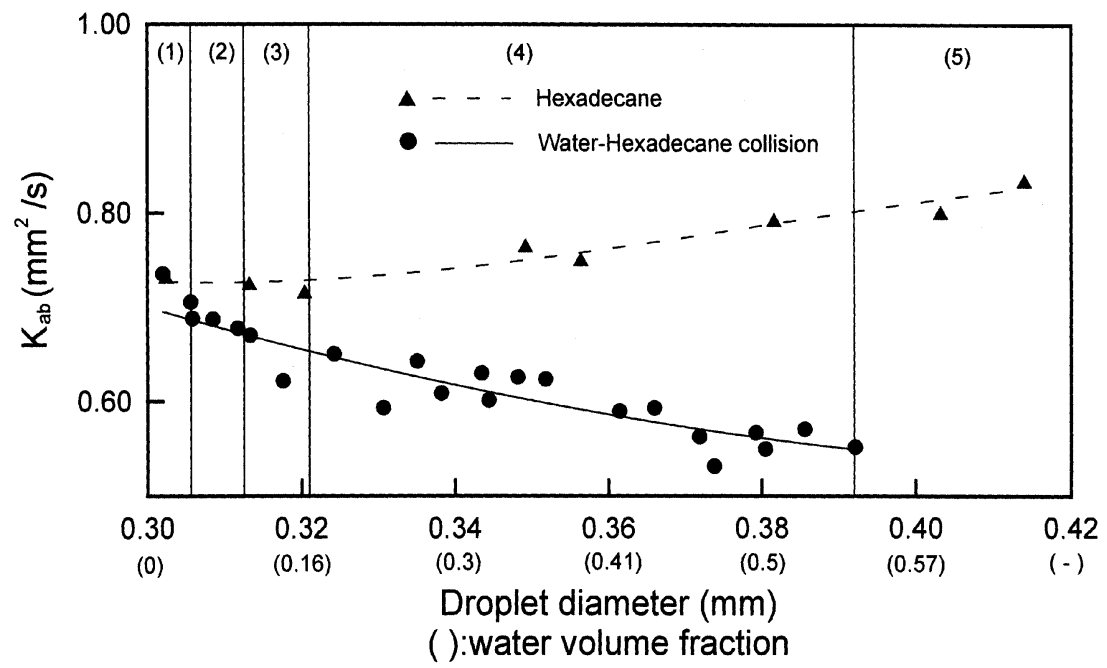

Figure 11. Average burning rates of collision-generated and pure hexadecane droplets. The various zones are defined in Figure 6. 


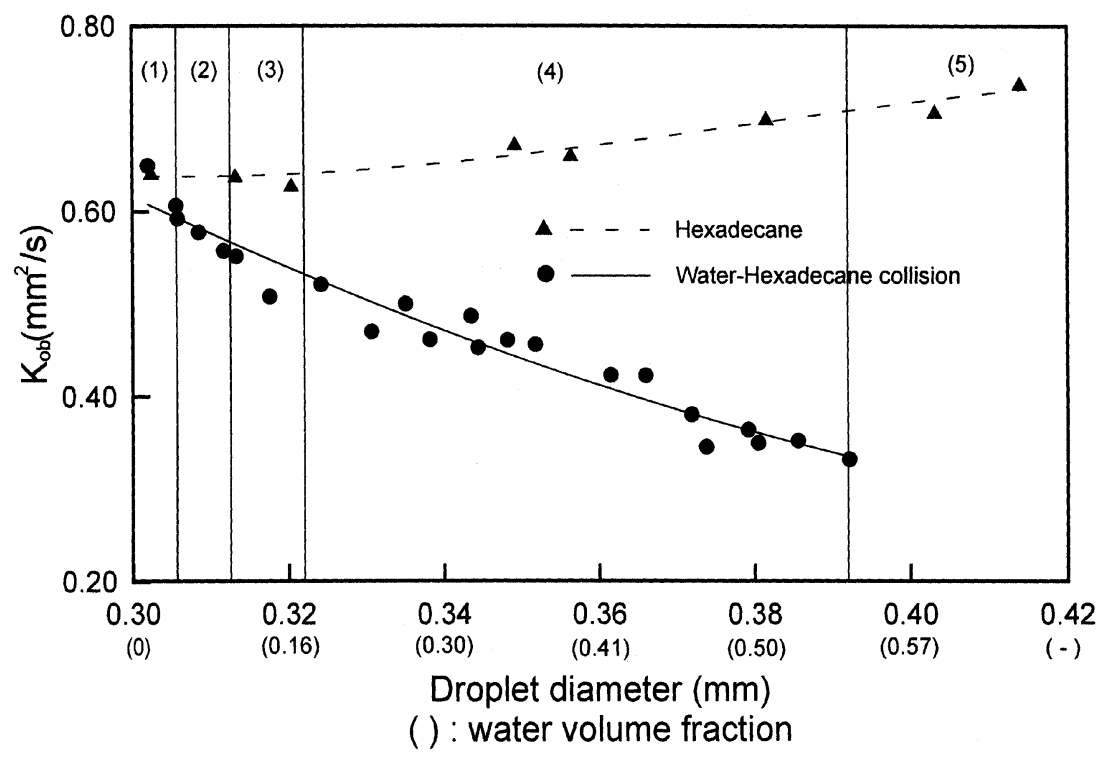

Figure 12. Overall burning rates of collision-generated and pure hexadecane droplets. The various zones are defined in Figure 6.

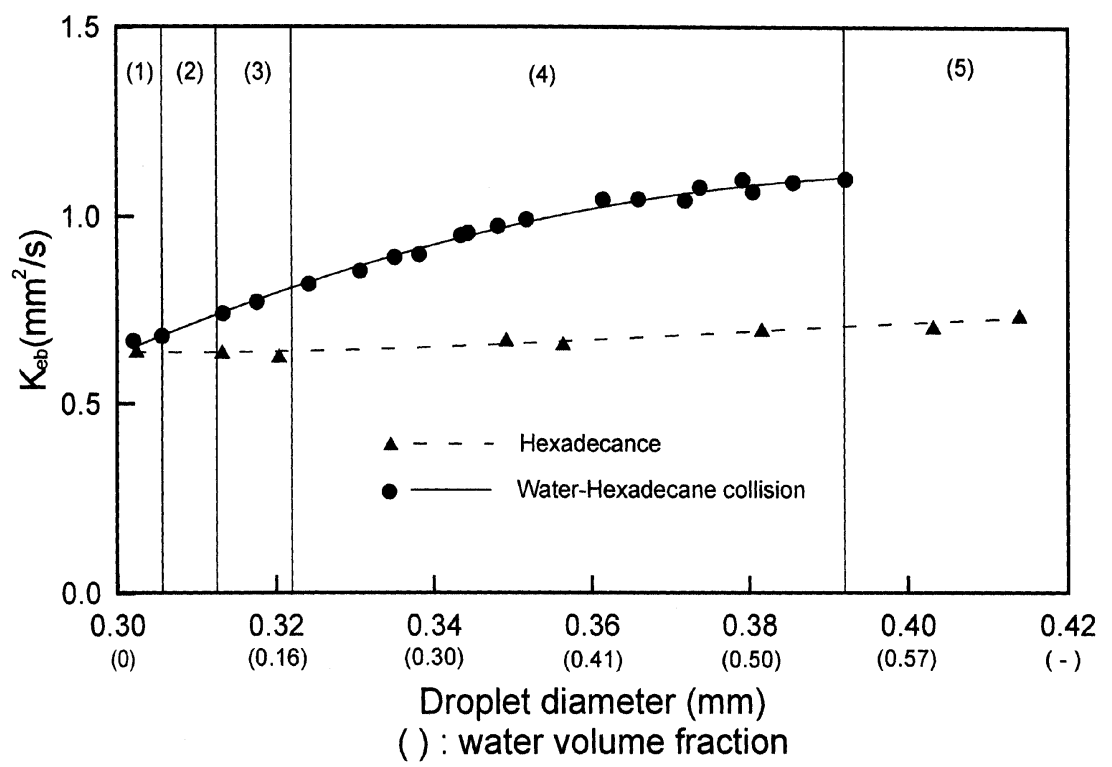

Figure 13. Effective burning rates of collision-generated and pure hexadecane droplets. The various zones are defined in Figure 6. 
However, because of the occurrence of either extinction or microexplosion, the burning times for the bicomponent droplets decreased with increasing droplet size. Furthermore, since the ignition delay increased with increasing droplet size, the droplet lifetime varied nonmonotonically with droplet size, as shown.

The average burning rate (Figure 11) represents the instantaneous droplet burning rate, the need for droplet heating, especially considering the higher heat capacity of the water droplet inside hexadecane, and the occurrence of extinction and microexplosion. Since droplet heating tended to reduce the average burning rate while the occurrence of extinction and microexplosion tended to increase it, the fact that it decreased with increasing droplet size for the bicomponent droplet indicates the importance of droplet heating, subsequent to ignition, in the burning process. The variation became even more severe if we included the influence of ignition delay in the definition of the overall burning rate, as shown in Figure 12.

The effective burning rate is meaningful for droplets that were completely burned out, with or without microexplosion. If microexplosion occurred, the droplet disappeared almost immediately after the explosion, implying that a droplet with given size existed only from the instant it was introduced to the combustion environment until it exploded. Consequently, the effective burning rate represents the most practical description of the various factors affecting droplet burning. Figure 13 shows that, while the average and overall burning rates decreased with increasing droplet size and, hence, water content, the effective burning rate, with the aid of microexplosion, actually increased. Compared with the results of hexadecane at the same droplet size, the effective burning rate could be almost doubled.

\section{CONCLUDING REMARKS}

Results and understanding gained from the present study can be summarized in the following:

1. Droplet of two immiscible liquids, water and $n$-hexadecane in the present study, can merge upon collision. The merging is of either the adhesive or insertive mode, with the latter being the dominated mode at high temperatures except for very high water contents. 
2. The trend of the ignition delay can be explained quite well by the concept of physical delay. The ignition delay increases with increasing droplet size for pure fuels and with increasing water content for collision-generated droplets. The ignition delay of the merged droplet is longer than that of pure hexadecane for the same droplet size, whereas it is shorter than that of the emulsion droplet for the same water content. In general, for the same droplet size, we have $t_{\text {ig }}$ (pure hexadecane $)<t_{\text {ig }}$ (collision-generated) $<t_{\text {ig }}$ (emulsion).

3. Judging from the flame color, only hexadecane is vaporized and burned prior to extinction or microexplosion. This is also supported by the result that the mass of the droplet at microexplosion is almost the same as the initial amount of water. The high heat capacity of water within the droplet simply serves as a heat sink.

4. Two types of droplet microexplosion were observed. The most frequent occurrence is reasoned to be induced by flash vaporization as the embedded water droplet is exposed to the ambience, instead of through homogeneous nucleation when it is still embedded within hexadecane. Microexplosion can also be occasionally induced by air bubbles trapped upon droplet collision.

5. Microexplosion induced by flash vaporization is violent, with the droplet rupturing into a mist. Microexplosion induced by trapped air bubbles is gentle, with the droplet rupturing into pieces.

6. The average burning rate is reduced with water addition because of the increased need for droplet heating. However, with the aid of microexplosion, the effective burning rate increases as water content increases. Consequently, the effective burning rates are rank-ordered as $K_{\text {eff }}$ (collision-generated) $>K_{\text {eff }}$ (emulsion) $>K_{\text {eff }}$ (pure hexadecane).

\section{REFERENCES}

Ashgriz, N. and Givi, P. (1987) Binary collision dynamics of fuel droplets. Int. J. Heat Fluid Flow, 8, 205.

Ashgriz, N. and Poo, J.Y. (1990) Coalescence and separation in binary collision of liquid drops. J. Fluid Mech., 221, 183.

Blander, M. and Katz, J.L. (1975) Bubble nucleation in liquids. AICHE J., 21, 833.

Chung, S.H. and Law, C.K. (1986) An experimental study of droplet extinction in the absence of external convection. Combust Flame, 64, 237.

Cornet, I. and Nero, W.E. (1955) Emulsified fuels in compression ignition engines. Ind. Eng. Chem., 47, 2133-2141. 
Greeves, G., Khan, I.M., and Onion, G. (1976) Effects of Water Induction on Diesel Engine Combustion and Emissions. Proc. Combust. Instit., 16, 321.

Hopkinson, B.P. (1913) Proceedings of the Institute of Mechanical Engineering, I. M. E. Proceedings, 679.

Ivanov, V.M. and Nefedov, P.I (1965) Experimental Investigation of the Combustion Process of Natural and Emulsified Liquid Fuels, NASA Tech. Translation TTF-258.

Jiang, Y.J., Umemura, A., and Law, C.K. (1992) An experimental investigation on the collision behavior of hydrocarbon droplets. J. Fluid Mech., 234, 171.

Lasheras, J.C., Fernandez-Pello, A.C., and Dryer, F.L. (1979) Initial observations on the free droplet combustion characteristics of water-in-fuel emulsions. Combust. Sci. Technol., 21, 1.

Law, C.K. (1977) A model for the combustion of oil/water emulsion droplets. Combust. Sci. Technol., 17, 29.

Law, C.K. (1978) Theory of thermal ignition in fuel droplet burning. Combust. Flame, 31, 285.

Law, C.K. and Williams, F.A. (1972) Kinetics and convection in the combustion of alkane droplets. Combust. Flame, 19, 393.

Murayama, T. (1978) Experimental Reduction of $N O_{x}$, Smoke and BSFC in a Diesel Engine Using Uniquely Produced Water to Fuel Emulsion, SAE Paper 780224.

Owens, E.C. and Wright, B.R. (1976) Engine Performance and Fire-Safety Characteristic of Water-Containing Diesel Fuels, Army Fuels and Lubricants Research Laboratories Interim Report No. AFLRL 83.

Qian, J. and Law, C.K. (1997) Regimes of coalescence and separation in droplet collision. J. Fluid Mech., 331, 59.

Sangiovanni, J.J. and Kesten, A.S. (1977) A theoretical and experimental investigation of the ignition of fuel droplets. Combust. Sci. Technol., 16, 59.

Turner, D.W. and Siegmund, C.W. (1973) Control of $\mathrm{NO}_{\mathrm{x}}$ from Fuel Oil Combustion: Water in Oil Emulsions, Winter Symposium of the IEC Division of the American Chemical Society, Washington, DC.

Valdmanis, E. and Wulfhorst, D.E. (1970) The Effect of Emulsified Fuels and Water Induction on Diesel Combustion, SAE Paper 700736.

Wang, C.H. and Chen, J.T. (1996) An experimental investigation of the burning characteristics of water-oil emulsions. Int. Commun. Heat Mass Transfer, 23, 823.

Wang, C.H. and Law, C.K. (1985) Microexplosion of fuel droplets under high pressure. Combust. Flame, 59, 53.

Wang, C.H. and Ni, L.H. (1996) The feasibility study of water-oil emulsion in diesel engine. Chinese J. Mech., 12, 465.

Wang, C.H., Hung, W.G., Fu, S.Y., Huang, W.C., and Law, C.K. (2003) On the burning and microexplosion of collision-generated bi-component droplets: Miscible fuels. Combust. Flame, 134, 289-300.

Weast, R.C. (1980) Handbook of Chemistry and Physics, CRC Press, Boca Raton, FL. 